\title{
A Docência do Ensino Superior sob a Égide dos Saberes de Morrin
}

\author{
ete Correia Amaro da Silva ${ }^{l}$, Marlene Menezes de Souza Teixeira ${ }^{2}$; Rita Edevanira de Sá Carneiro ${ }^{3}$
}

\begin{abstract}
Resumo: O presente trabalho visa discutir a importância dos sete saberes docentes necessários para a prática pedagógica no ensino superior, tomando como referência os trabalhos de Tardif (2002), Saviani (1996), Tardif e Gauthier (1996), Pimenta (1999), Pollard e Tann (1987), Garcia (1997) e Morin, que têm procurado mostrar a importância da pedagogia para a formação, atuação e desenvolvimento dos professores. Os autores aqui indicados refletem acerca dos sete saberes necessários à Educação do Futuro, onde Edgar Morin (2004) apresenta idéias que podem contribuir para que o educador possa redefinir sua posição nas instituições de ensino superior, nas relações com os estudantes, o currículo, as disciplinas e a avaliação. A metodologia aqui utilizada parte da reflexão sobre a educação do Ensino Superior, aprofundando-se na visão de Morim que expõe sobre os sete saberes numa perspectiva ética, revelando o compromisso com uma educação integral, de qualidade e humanista. Neste contexto, conclui-se que é preciso identificar e analisar a docência universitária diante dos desafios da realidade nacional num mundo globalizado, partindo do princípio de que a docência sofre influências da realidade na qual está inserida e que, nesta se encontra, a relação Estado/Universidade/Professor. Logo, a docência do ensino superior deve estar respaldada nos eixos e saberes do filósofo Morin, que marca a construção da teoria e da prática-pedagógica.
\end{abstract}

Palavras-chave: Docência, Ensino Superior, Saberes

\section{The Teaching in Higher Education by the Aegis of Morrin Knowledge}

\begin{abstract}
This paper aims to discuss the importance of the seven teaching knowledge needed for teaching practice in higher education, with reference to the work of Tardif (2002), Saviani (1996), Gauthier and Tardif (1996), Pepper (1999), Pollard and Tann (1987), Garcia (1997) and Morin, who have sought to show the importance of pedagogy for the formation, operation and development of teachers. The authors listed here reflect on the seven knowledge necessary to Education of the Future, where Edgar Morin (2004) presents ideas that can help the educator can redefine its position in higher education institutions, relations with students, the curriculum, the disciplines and evaluation. The methodology used here of the debate on education Higher Education, deepening the vision of Calico that expounds on the seven knowledge from an ethical perspective, revealing the commitment to a comprehensive education, quality and humanist. In this context, it is concluded that it is necessary to identify and analyze the challenges of university teaching on the national reality in a globalized world, assuming that teaching is influenced by the reality in which it operates and that this is the relationship status / University / Teacher . Thus the teaching of higher education must be supported on the axles and knowledge of the philosopher Morin , marking the construction of the theory and practice - teaching .
\end{abstract}

Keywords: Teaching , Higher Education , Knowledge

\footnotetext{
${ }^{1}$ Graduada em História pela Universidade Regional do Cariri - URCA. Especialista em História e Sociologia (URCA) Especialista em Metodologia e Docência do Ensino Superior (FVJ).E-mail: francyamaro@yahoo.com.br ou franci_maxi2012@hotmail.com.br;

${ }^{2}$ Graduada em Enfermagem pela Universidade Estadual do Ceará. Doutoranda em Educação e Ciências: Química da Vida e da Saúde, pela Universidade Federal do Rio Grande do Sul - UFRGS.

${ }^{3}$ Graduada em Ciências Biológicas pela Universidade Regional do Cariri -URCA. Especialista em Gestão Escolar e em Mídias na Educação pela Universidade Federal do Ceará -UFC. E-mail: edevanira@yahoo.com.br.
} 


\section{Introdução}

A mobilização dos saberes dos professores, bem como os saberes da docência, são um passo importante para mediar o processo de construção da identidade profissional dos professores, os Saberes de Edgar Morin são os saberes produzidos historicamente pela humanidade, conforme argumenta Pimenta (1999).

O primeiro saber anunciado por Morin (2000) traz à tona as cegueiras do conhecimento, em particular o erro e a ilusão. O segundo saber diz respeito aos princípios do conhecimento pertinente, o que contraria a fragmentação, a disciplinarização e traz a idéia de rearticulação desta em outros contextos. A condição humana, exposta no terceiro saber, possibilita indagar sobre quem somos, enquanto ser humano constituído de humanidade e do que o caracteriza enquanto tal, de onde vem e para onde vai a humanidade.

O quarto saber apontado por Morin, à compreensão passa pela idéia de que o planeta se constitui como um turbilhão em movimento, desprovido de um centro organizador, porém autoorganizador e co-organizador, que gerencia o caos e a desorganização, utilizando dos elementos que dispõe para tal. O quinto saber é parte de todo pensamento, planejamento e organização de qualquer atividade acadêmica. Ao passo que se deve ensinar que o conhecimento, seja ele senso comum ou conhecimento científico, sempre é permeado pela incerteza.

Enquanto o sexto saber apresentado por Morin, ensina a compreensão entre as pessoas, a convivência da diferença em contextos de igualdade e solidariedade intelectual.

O sétimo saber postulado por Morin, a ética do gênero humano, remete a uma antropoética, que envolve uma cadeia de três termos, indivíduo, sociedade e espécie. Sob esse aspecto, nota-se que os sabres são constituídos também pelos quatro pilares da educação e as concepções reflexivas, a partir dos quais os saberes pedagógicos viabilizam a ação do ato de ensinar.

Neste sentido, os aspectos supracitados tendem a identificar o que é necessário saber para ensinar, no que tange a prática reflexiva, onde o docente deve ser capaz de organizar uma pedagogia construtivista, criar situações de aprendizagem, experimentar e corrigir, por intermédio do diálogo estabelecido com sua realidade de trabalho, e sua atuação.

\section{Os Saberes Docentes de Morin}

São saberes necessários ao Ensino Superior, formando uma espécie de reservatório no qual o docente se abasteceria para responder às exigências específicas de situações concretas de ensino. 
Os Sete Saberes indispensáveis enunciados por Edgar Morin compreende: as cegueiras do conhecimento: O erro e a ilusão; Os princípios do conhecimento pertinente; Ensinar a condição humana; Ensinar a identidade terrena; Enfrentar as incertezas; Ensinar a compreensão; e A ética do gênero humano.

Ambos constituem eixos e, ao mesmo tempo, caminhos que se abrem a todos os que pensam, fazem educação, e que estão preocupados com o futuro da vida acadêmica. Freire (1996, p. 159-160), na reflexão sobre ensinar exige que haja certo nível de afetividade para com os estudantes e ressalta que:

\begin{abstract}
Não é certo, sobretudo do ponto de vista democrático, que serei tão melhor professor quanto mais severo, mais frio, mais distante e "cinzento" me ponha nas minhas relações com os alunos (...). A afetividade não se acha excluída da cognoscibilidade. $\mathrm{O}$ que não posso obviamente permitir é que minha afetividade interfira no cumprimento ético de meu dever de professor no exercício de minha autoridade. Não posso condicionar a avaliação do trabalho escolar de um aluno ao maior ou menor bem querer que tenha por ele.
\end{abstract}

Tendo em vista que a prática profissional do docente não é um mero oficio de aplicação de teorias; e sim, um espaço de produção de saberes e conhecimentos usados no desenvolvimento profissional e em sua emancipação. Atentos a essa questão, Pimenta e Anastasiou (2002, p.259), referindo-se ao processo de docência do ensino superior, dizem que:

O avançar no processo de docência e do desenvolvimento profissional, mediante a preparação pedagógica não se dará em separado de processos de desenvolvimento pessoal e Institucional: este é o desafio a ser hoje, considerado na construção da docência no ensino superior

MORIN (2004) apresenta idéias que podem contribuir para o educador redefinir a sua posição nas instituições de ensino nas relações com os estudantes, o currículo, as disciplinas e a avaliação.

\title{
O erro e a ilusão
}

A ciência se acostumou a afastar o erro de suas concepções, contudo é preciso considerar o erro e a ilusão constantes nas concepções para que o conhecimento avance, visto que todo conhecimento comporta o risco do erro e da ilusão.

A educação deve mostrar que não há conhecimento que não esteja, em algum grau, ameaçado pelo erro e pela ilusão. [...] O conhecimento não é um espelho das coisas ou do mundo externo. Todas as percepções são ao mesmo tempo, traduções e 
reconstruções cerebrais com base em estímulos ou sinais captados e codificados pelos sentidos (MORIN, 2004, p.19-20)

Da mesma forma, o conhecimento do conhecimento deve aparecer como necessidade primeira, que serviria de preparação para enfrentar os riscos permanentes de erro e de ilusão, que não cessam de parasitar a mente humana; trata-se de armar cada mente no combate vital rumo à lucidez.

É necessário introduzir e desenvolver na educação estudo das características cerebrais, mentais e culturais dos conhecimentos humanos, de seus processos e modalidades, das disposições tanto psíquicas quanto culturais que o conduzem ao erro ou à ilusão. Tendo em vista que,

O desenvolvimento do conhecimento científico é poderoso meio de detecção dos erros e de luta contra as ilusões. Entretanto, os paradigmas que controlam a ciência podem desenvolver ilusões, e nenhuma teoria científica está imune para sempre contra o erro. Além disso, o conhecimento científico não pode tratar sozinho dos problemas epistemológicos, filosóficos e éticos. (MORIN, 2004, p.19-20)

É impressionante que a educação que visa transmitir conhecimentos seja cega ao que vêm a ser o conhecimento humano, seus dispositivos, enfermidades, dificuldades, tendências ao erro e à ilusão, e não se preocupe em fazer conhecer o que é o conhecimento de fato.

O erro e a ilusão são inseparáveis do ato de conhecer, pois o conhecimento é uma reflexão da percepção humana, e esta pode vir a ser decisiva na comunicação humana.

\section{Conhecimento pertinente}

Para que o conhecimento seja pertinente a educação deve tomar o contexto, o global, o multidimensional e o complexo evidentes. MORIN (2004) defende que não é preciso aniquilar a idéia da disciplina, mas rearticular a idéia da disciplina em outros contextos.

Freire \& Shor (1997, p.18) esclarecem esta questão de forma muito convincente, ao passo que:

Se observarmos o ciclo do conhecimento, podemos perceber dois momentos, e não mais do que dois, dois momentos que se relacionam dialeticamente. $\mathrm{O}$ primeiro momento do ciclo, ou um dos momentos do ciclo, é o momento da produção, da produção de um conhecimento novo, de algo novo. O outro momento é aquele em que o conhecimento produzido é conhecido ou percebido. Um momento é a produção de um conhecimento novo e o segundo é aquele em que você conhece o conhecimento existente. O que acontece, geralmente, é que dicotomizamos esses dois momentos, isolamos um do outro. Conseqüentemente, reduzimos o ato de conhecer do conhecimento existente a uma mera transferência do conhecimento existente. 
Nesse aspecto, Morin afirma que o maior desafio que a escola necessita enfrentar, hoje, é o de promover uma reforma do pensamento que resulte numa produção de conhecimentos pertinentes, pois segundo ele,

A reforma do pensamento é que permitiria o pleno emprego da inteligência para responder a esses desafios e permitiria a ligação de duas culturas dissociadas. Tratase de uma reforma não programática, mas paradigmática, concernente a nossa aptidão para organizar o conhecimento. MORIN (2000, p. 20)

Há ciências que já praticam o conhecimento pertinente, que vem a ser uma idéia contra a fragmentação, como a Ecologia ao juntar áreas variadas do conhecimento. É o produto do pensamento complexo, interfere na construção de conhecimentos variados por meio da contextualização e requer a participação das diferentes dimensões do individuo que aprende, como as emotivas e corporais e não apenas as mentais.

O conhecimento pertinente permite acima de tudo estabelecer relações, a sociedade vigente vive de conhecimentos separados, fato este que deveria ser religado e revisado por uma pedagogia e pelo ensino do conhecimento introduzindo tudo num sistema planetário, global.

\section{Condição humana}

Existem multidimensionalidades, além de seres culturais o individuo é, também, natural, físico, psíquico, mítico e imaginário. É necessário reconhecer a própria condição humana de dualidade, expressa na idéia de homo sapiens, afinal conhecer o humano é situá-lo no universo. Conforme as reflexões de Morin em sua tese sobre Educação e complexidade: os sete saberes e outros ensaios (2004),

Devemos reconhecer nosso duplo enraizamento no cosmos físico e na esfera viva e, ao mesmo tempo, nosso desenraizamento propriamente humano. Estamos simultaneamente dentro e fora da natureza. (MORIN, 2004, p.47-48)

Somos originários do cosmos, da natureza, da vida, mas, devido à própria humanidade, à nossa cultura, à nossa mente, à nossa consciência, tornamo-nos estranhos a este cosmos, que nos parece secretamente íntimo. [...] O humano é um ser a um só tempo plenamente biológico e plenamente cultural, que traz em si a unidualidade originária. (MORIN, 2004, p.51-52)

O homem somente se realiza plenamente como ser humano pela cultura e na cultura. Não há cultura sem cérebro humano (aparelho biológico dotado de competências para agir, perceber, saber, aprender), mas não há mente (mind), isto é, capacidade de consciência e pensamento, sem cultura. (MORIN, 2004, p.52) 
O homem não nasceu humano, ele se tornou humano devido a um processo de aprendizado constante, marcado por evoluções, tradições, culturas, adaptações. A educação traz essa necessidade real de restaurar a unidade fragmentada do conhecimento, de modo que cada ser humano tome consciência, ao mesmo tempo de sua identidade complexa e de sua identidade que é comum a todos os outros seres humanos. (MORIN, 2004, p.15)

Partindo do pressuposto de que o ser humano é ou seria a um só tempo físico, biológico, psíquico, cultural, social e histórico. Seria uma unidade complexa da natureza humana, totalmente desintegrada na educação por meio das disciplinas, que tem se tornado impossível aprender o que significa ser humano. Na mobilização de todas as aptidões humanas a condição humana seria resgatada de modo peculiar como se fosse o objeto primordial de todo o ensino.

\section{Identidade terrena}

Dos sete saberes de Morin, ensinar a identidade terrena está ligada a idéia da sustentabilidade, partindo do pressuposto de ensinar que a Terra é um pequeno planeta e precisa ser sustentado a qualquer custo, isso significa construir um planeta viável para as futuras gerações.

Se o individuo não conseguir ter uma tomada de consciência e cultura para manter o planeta sem problemas e sinais de irritabilidade, como já é possível constatar, devido às transformações desencadeadas na era da globalização. No Brasil, a Lei de Diretrizes e Bases da Educação Nacional (9.394/96), no seu artigo $1^{\circ}$, ressalta que as manifestações culturais integram o processo formativo:

A educação abrange os processos formativos que se desenvolvem na vida familiar, na convivência humana, no trabalho nas instituições de ensino e pesquisa, nos movimentos sociais e organizações da sociedade e nas manifestações culturais.

$\mathrm{O}$ ensino da identidade terrena induz a um viés cujo respaldo esta no fato de que a crise planetária que afeta o século XXI mostra todos os seres humanos vivendo os mesmos dilemas e a priori com o mesmo destino comum.

O grande desafio para a educação planetária seria proporcionar a valorização das múltiplas identidades que integram a humanidade que habita o planeta e que leve os estudantes a valorizar suas origens étnicas, a história e a cultura como um todo. Segundo Morin (2002, p. 64)

A cultura constitui a herança social do ser humano: as culturas alimentam as identidades individuais e sociais no que elas têm de mais específico. Por isso, as culturas podem mostrar-se incompreensíveis ao olhar das outras culturas, incompreensíveis umas para as outras. 
Logo, a identidade humana é a reunião de fragmentos da sociedade e da espécie humana, ambos têm em si a criança e o adulto, com a mesma natureza, mas dentro delas desenvolvem a diversidade através de culturas e crenças. A interdisciplinaridade aqui é fundamental para unir todos os espaços que envolvem a identidade humana.

É imprescindível que o homem viva em contínua conexão, construa mecanismos para sabe viver e conviver, a escola ainda é o lugar privilegiado para aquisição de conhecimentos, pois oportuniza a todos que nela se inserem numa experiência de vida em sociedade.

\title{
Enfrentar as incertezas
}

A ciência cartesiana criou a idéia de que todo viés científico pertence ao reino da certeza, Werner Heisenberg construiu o princípio da incerteza, ganhando um Prêmio Nobel; a tese afirma que um determinado elemento atômico pode se comportar simultaneamente como onda e partícula.

Os seres humanos, também seriam partículas e ondas; partículas enquanto seres individualizados e ondas como seres portadores de muitas multiplicidades. Conforme Morin, (2000 p. 91)

\begin{abstract}
O desejo de liquidar a Incerteza pode então nos parecer uma enfermidade própria a nossas mentes, e todo o direcionamento para a grande Certeza poderia ser somente uma gravidez psicológica. O pensamento deve, então, armar-se e aguerrir-se para enfrentar a incerteza. Tudo que comporta oportunidade comporta risco, e o pensamento deve reconhecer as oportunidades de riscos como os riscos das oportunidades.
\end{abstract}

Nessa perspectiva é preciso ensinar o princípio da incerteza, no qual o conhecimento científico, nunca é um produtor absoluto de certezas, ao contrário, tudo aquilo que foi criado pelo homem é crivado pela idéia da incerteza, que pode comandar o avanço do saber e da cultura.

- Um princípio de incerteza cérebro-mental, que decorre do processo de tradução/reconstrução próprio a todo conhecimento.

- Um princípio de incerteza lógica: como dizia Pascal muito claramente, "Nem a contradição é sinal de falsidade, nem a não-contradição é sinal de verdade."

- Um princípio da incerteza racional, já que a racionalidade, se não mantém autocrítica vigilante, cai na racionalização.

- Um princípio da incerteza psicológica: existe a impossibilidade de ser totalmente consciente do que se passa na maquinaria de nossa mente, que conserva sempre algo de fundamentalmente inconsciente. Existe, portanto, a dificuldade do auto-exame crítico, para o qual nossa sinceridade não é garantia de certeza, e existem limites para qualquer autoconhecimento. (MORIN 2000 p.84) 
A educação deve voltar-se para o estudo das incertezas racionais, cérebros-mentais, e psicológicas, que estão ligadas ao conhecimento e visam aprimorar o conhecimento adquirido pelos humanos. Esta idéia precisa ser incorporada no ensino da Física, Química, História, Geografia, Línguas, Filosofia, da Sociologia.

\section{Ensinar a compreensão}

As instituições de ensino superior são caracterizadas pela incompreensão: disciplinas que brigam com as outras, departamentos que não se entendem com os outros, áreas do conhecimento que não se falam.

Nesse âmbito haveria um interesse produtivo na introdução do ensino da compreensão nas unidades de ensino superior e em qualquer nível, pois a idéia da compreensão pode ser estendida ao planeta tendo em vista o fato de precisar de mais compreensão.

Para Morin (2000 p. 95-96)

A compreensão do sentido das palavras de outro, de suas idéias, de sua visão do mundo está sempre ameaçada por todos os lados:

- Existe o "ruído" que parasita a transmissão da informação, cria o malentendido ou o não-entendido.

- Existe a polissemia de uma noção que, enunciada em um sentido, é entendida de outra forma; assim, a palavra "cultura", verdadeiro camaleão conceptual, pode significar tudo que, não sendo naturalmente inato, deve ser aprendido e adquirido; pode significar os usos, valores, crenças de uma etnia ou de uma nação; pode significar toda a contribuição das humanidades, das literaturas, da arte e da filosofia.

- Existe a ignorância dos ritos e costumes do outro, especialmente dos ritos de cortesia, o que pode levar a ofender inconscientemente ou a desqualificar a si mesmo perante o outro.

- Existe a incompreensão dos Valores imperativos propagados no seio de outra cultura, como o são nas sociedades tradicionais o respeito aos idosos, a obediência incondicional das crianças, a crença religiosa ou, ao contrário, em nossas sociedades democráticas contemporâneas, o culto ao indivíduo e o respeito às liberdades.

- Existe a incompreensão dos imperativos éticos próprios a uma cultura, o imperativo da vingança nas sociedades tribais, o imperativo da lei nas sociedades evoluídas.

- Existe freqüentemente a impossibilidade, no âmago da visão do mundo, de compreender as idéias ou os argumentos de outra visão do mundo, como de resto no âmago da filosofia, de compreender outra filosofia.

- Existe, enfim e sobre tudo, a impossibilidade de compreensão de uma estrutura mental em relação á outra.

Logo o que caracteriza hoje o planeta, enquanto terra, pátria, é a incompreensão política, ideológica, econômica. Ao passo que a compreensão deveria ser o meio e o fim da comunicação 
humana, sempre voltada para a harmonia nas universidades, a incompreensão produz o embrutecimento e torna o individuo incapaz de compreender a simplicidade do conhecimento e da vida humana.

\section{Ética do gênero humano}

Ética é uma palavra de entendimento complexo, que poderia ser resumida com a seguinte expressão: não desejar para os outros, aquilo que você não deseja para você. A antropoética seria por tanto a ética do gênero humano, por isso seu ensino precisa ser reintroduzido nas instituições de ensino superior, tendo em vista o fato de estar ancorada em três elementos: o indivíduo, a sociedade e a espécie.

A antropoética supõe a decisão consciente e esclarecida de:

- assumir a condição humana indivíduo/sociedade/espécie na complexidade do nosso ser;

- alcançar a humanidade em nós mesmos em nossa consciência pessoal;

- assumir o destino humano em suas antinomias e plenitude.

A antropoética instrui-nos a assumir a missão antropológica do milênio:

$>$ trabalhar para a humanização da humanidade;

$>$ efetuar a dupla pilotagem do planeta: obedecer à vida, guiar a vida;

$>$ alcançar a unidade planetária na diversidade;

$>$ respeitar no outro, ao mesmo tempo, a diferença e a identidade quanto a si mesmo;

$>$ desenvolver a ética da solidariedade;

$>$ desenvolver a ética da compreensão;

$>$ ensinar a ética do gênero humano.

(MORIN, 2000, p.106)

No intuito de religar esses elementos éticos, a antropoética propõe a humanização do individuo, passando a fazer parte do todo, contribuindo para que o ser humano desenvolva conjuntamente a autonomia pessoal, a integração social e cultural, bem como a democracia, que na visão de Morin,

Necessita ao mesmo tempo de conflitos de idéias e de opiniões, que lhe conferem sua vitalidade e produtividade. Mas a vitalidade e a produtividade dos conflitos só podem se expandir em obediência às regras democráticas que regulam os antagonismos, substituindo as lutas físicas pelas lutas de idéias, e que determinam, por meio de debates e das eleições, o vencedor provisório das idéias em conflito, aquele que tem, em troca, a responsabilidade de prestar contas da aplicação de suas idéias. (MORIN, 2000, p.108) 
Morin argumenta que somente através da integração entre indivíduos é que se produz a sociedade, expressando a ética da solidariedade e do gênero humano.

\section{Os Quatro Pilares da Educação e as Concepções Reflexivas}

Um dos maiores desafios do século atual, onde os indivíduos estão em busca de raízes e referências. A educação e o fato de aprender a viver juntos no mundo globalizado emergem como o grande trunfo, por possibilitar o desenvolvimento contínuo de pessoas e sociedades.

No relatório encaminhado à UNESCO (Organização das nações unidas para a Educação, a Ciência e a Cultura), a Comissão Internacional de Estudos sobre a Educação para o século XXI sublinha que, para dar respaldo e resposta as inúmeras missões sobre a Educação, inclusive do Ensino Superior deve estar organizada em torno de quatro aprendizagens fundamentais:

1. Aprender a conhecer: (Adquirir cultura geral ampla e domínio aprofundado de um reduzido número de assuntos, mostrando a necessidade de educação contínua e permanente);

2. Aprender a fazer: (Oferecendo oportunidades de desenvolvimento de competências amplas para enfrentar o mundo do trabalho);

3. Aprender a conviver:

(Cooperar com os outros em todas as atividades humanas);

4. Aprender a ser:

(Que integra as outras três, criando condições que favoreçam ao indivíduo adquirir autonomia e discernimento).

Nesses termos, a docência do ensino superior requer segundo a concepção reflexiva e seus pressupostos o desenvolvimento autocrítico, no intuito de que o docente seja capaz de realizar uma análise do seu ensino, adquirir competências cognitivas e relacionais.

Assim, considerando-se estudos de Pollard e Tann (1987) em textos de Garcia (1997), ao refletirem sobre os modelos de ensino reflexivo destacam as seguintes destrezas que são consideradas referencias para a Docência do Ensino Superior:

\section{DESTREZAS EMPIRICAS:}

Capacidade de diagnóstico tanto em nível de sala de aula como da escola. Implica a capacidade de compilar dados, descrever situações, processos, causas e efeitos. Requerendo dados objetivos e subjetivos (sentimentos, afetos); 


\section{DESTREZAS ANALITICAS:}

Capacidade para analisar dados descritivos compilados e a partir deles, construir uma teoria;

\section{DESTREZAS AVALIATIVAS:}

Se prendem com o processo de valorização, de emissão de juízos sobre as conseqüências educativas dos projetos e com a importância dos resultados alcançados;

\section{DESTREZAS ESTRATEGICAS:}

Capacidades de planejamento da ação, à antecipação da sua implantação seguindo a análise realizada;

\section{DESTREZAS PRÁTICAS:}

Capacidade de relacionar a analise com a prática, com os fins e com os meios, para obter um efeito satisfatório;

\section{DESTREZAS DE COMUNICAÇÃO:}

Os profissionais reflexivos necessitam de comunicar e partilhar as idéias com outros colegas, o que sublinha a importância das atividades de trabalho e de discussão em grupo.

Os Sete Saberes Necessários à Educação do Futuro, e o Relatório de Jacques Delors remetem a reflexão de algumas práticas que podem ajudar na preparação de estratégias eficientes dentro do novo paradigma que se descortina na educação.

Ao enfocar a questão dos saberes para a docência do ensino superior é preciso considerar os estudos do pesquisador Tardif (2002), que analisa os saberes profissionais e sua relação com a profissionalização/formação docente.

Ao passo que em sua abordagem de docência reflexiva e seus saberes para o século XXI, são colocados em pauta competências necessárias aos docentes, mostrados como novo campo para a pesquisa e ainda muito pouco explorado pelas ciências da educação.

Ao considerar as transformações do mundo contemporâneo, onde cada vez mais exige cidadãos independentes, de iniciativa, que saibam comunicar-se e ter flexibilidade na resolução de conflitos, pode-se dizer que os estudantes estarão aptos a aventurar-se pelos domínios do saber e do desconhecido? Conforme Edgar Morin, 
responsabilidades sociais), ou seja, a nossa participação no gênero humano, pois compartilhamos um destino comum (MORIN, 2000 p. 18).

Desse modo, pensar na educação do século XXI é pensar em uma sociedade da aprendizagem. Onde o trabalho é baseado no compromisso com a qualidade, no respeito à diversidade, na construção de competências e na valorização do indivíduo de forma integral.

Com base nos Saberes de Morin e nos Pilares da Educação de Delors é preciso realizar algumas ações estratégicas e políticas públicas que fortaleçam o papel do docente no mundo globalizado e complexo mediado pelas tecnologias.

\section{Conclusão}

Buscar construir novas realidades educativas a partir dos sete saberes implica uma transformação na vida das pessoas, das instituições de ensino e uma redefinição do currículo. Não se trata de currículos de generalidades, ao contrário, o objetivo seria pensar o currículo buscando religar os conhecimentos, as disciplinas e os saberes.

Nessa perspectiva existem diversas escolas e universidades que se preocupam com a formação integral do ser humano priorizando o homem, o sistema, o cosmos, a ecologia com base principalmente na ética. Entretanto, a identificação de tais valores na prática cotidiana só é possível com o envolvimento de toda a comunidade educacional.

O propósito dos Sete Saberes ou como aplicar os sete saberes na reforma da educação e no ensino superior é um problema a ser discutido e decidido coletivamente nas instituições de ensino, visto que podem contribuir para juntar as disciplinas.

$\mathrm{Na}$ prática se propõe uma redefinição dos currículos que integrem os saberes e propiciem a formação e as ações de um novo tipo de professor, onde o pensamento complexo não é contra a disciplina, mas abre outros campos para a disciplina. Sua introdução no ensino superior pode levar possivelmente para rumos inovadores na construção do conhecimento.

Em resumo, os maiores propósitos dos saberes de Edgar Morin resumem-se em revisar currículos; integrar as disciplinas e religar os saberes; reorganizar o pensamento; abrir outros campos de saberes; recusar a separação entre razão e emoção, ciência e arte, ciência e mito; estimular o diálogo entre diferentes, reconhecendo que pode haver relações de tensão entre opostos (singular e universal; local e global; sujeito e objeto).

Nesse âmbito, seria possível criar estratégias de formação que propiciem a revelação da finalidade da aprendizagem, do conteúdo, que levem o docente a se conscientizar dos objetivos propostos, que são importantes para o desenvolvimento do pensamento reflexivo e da autonomia. 


\section{Referencias}

BRASIL. Lei de Diretrizes e Bases da Educação. Brasília: MEC, 1996.

CARVALHO, Edgard de Assis. Morin. São Paulo: Atta -Mídia e Educação, 2006. (Coleção Grandes Educadores).Vídeo, 55min.MORIN, Edgar. Os sete saberes necessários à educação do futuro. 9.ed. São Paulo: Cortez; Brasília, DF: UNESCO,2004. Slides organizados por Sandra Freitas, em 2010, para atender o Curso - Prática Docente no Ensino Superior, realizado pela UFPA.

CHAKUR, CRSL. Desenvolvimento profissional docente: contribuições de uma leitura piagetiana. Araraquara (SP): JM Editora; 2001.

FREIRE, Paulo. Pedagogia da autonomia: saberes necessários à prática educativa. São Paulo: Ática, 1996. Terra, 2002 .

Paulo. Pedagogia da autonomia: saberes necessários à prática educativa. São Paulo: Paz e

FREIRE, Paulo \& SHOR, Ira. Medo e Ousadia. Rio de Janeiro: Paz e Terra, 1997.

GARCIA, Carlos Macêdo. A formação de professores: centro de atenção e pedra-de-toque. IN NÓVOA, Antônio. Os professores e sua formação. Lisboa Dom Quixote, 1997.

MARCELO, García C. Formação de professores: para uma mudança educativa. Portugal (PT): Porto; 1999.

MORIN, Edgar, 1921- Os sete saberes necessários à educação do futuro / Edgar Morin ; tradução de Catarina Eleonora F. da Silva e Jeanne Sawaya ; revisão técnica de Edgard de Assis Carvalho. - 2. ed. - São Paulo : Cortez ; Brasília, DF : UNESCO, 2000.

MORIN, Edgar. A cabeça bem-feita: repensar a reforma, reformar o pensamento. Rio de Janeiro: Bertrand Brasil, 2000.

MORIN, Edgar. O método V: a humanidade da humanidade. Porto Alegre: Sulina, 2002.

Educação e complexidade: os sete saberes e outros ensaios. São Paulo: Cortez, 2004

Os sete saberes necessários à educação do futuro / Edgar Morin; tradução de Catarina Eleonora F. da Silva e Jeanne Sawaya; revisão técnica de Edgard de Assis Carvalho. - 2. ed. - São Paulo : Cortez ; Brasília, DF : UNESCO, 2000.

PIMENTA, Selma Garrido. Formação de professores: identidade e saberes da docência. In: (Org.). Saberes pedagógicos e atividade docente. São Paulo: Cortez, 1999.

PIMENTA, Selma Garrido; ANASTASIOU, Lea das Graças Camargo. Docência no ensino superior. São Paulo: Cortez, 2002.

POLLARD, A. \& TANN. S. Reflective Ensino na Escola Primária. Um Manual para a sala de aula. London: Cassell, 1989. 
TARDIF, Maurice; LESSARD, Claude; LAHAYE, Louise. Os professores face ao saber - esboço de uma problemática do saber docente. Teoria \& Educação, Porto Alegre, n. 4, 1991.

TARDIF, Maurice. Saberes docentes e formação de professores. Petrópolis (SP): Vozes; 2002.

\section{Como citar este artigo (Formato ABNT):}

SILVA, F.C.A.; TEIXEIRA, M.M.S. CARNEIRO, R.E.S. A Docência do Ensino Superior sob a Égide dos Saberes de Morrin. Id on Line Revista de Psicologia, Novembro de 2014, vol.8, n.24, p. 7-20. ISSN 19811189. 